\title{
Climate Change and Mental Health: Where do We Stand?
}

\author{
Suhasini Das ${ }^{1}$, Kangkan Pathak ${ }^{2}$
}

\begin{abstract}
Climate change is a serious public health crisis of international concern. It has been interconnected to chronic medical conditions also as psychological state and may propel the body's response to existing environmental assaults into overdrive. It is well documented that climate change causes significant stress and distress, anxiety-related responses as well as chronic and severe mental health disorders. The exiting literatures found that acute events have been associated with elevated levels of anxiety, depression, and post-traumatic stress disorders (PTSDs), and high-risk coping behaviors, such as alcohol use and abuse, aggressive behavior, post-traumatic stress, and domestic violence have also been associated with changing climate. The changes in climates have been directly connected to human activities and not merely due to normal patterns of nature. Thus, this article may act as a quick reference for those interested in studying the various physical and psychological aspects of climate change.

Keywords: Climate change, Environment, Mental health.

Eastern Journal of Psychiatry (2020): 10.5005/jp-journals-11001-0006
\end{abstract}

\section{INTRODUCTION}

The effects of climate change have become very obvious over the last few decades. Erratic and extreme weather events such as flash flood, forest fires, and drought are becoming commonplace and regular phenomena. Greenhouse gas emissions are at an all-time high, the earth is warming rapidly, polar ice caps are melting at an alarming rate, and species are disappearing faster than ever. We, humans being part of the ecosystem, are not immune to these consequences and as such they will impact our health, both physical and mental.

\section{Effects on Physical Health}

The World Health Organization (WHO) estimates an increase of 2,50,000 excess deaths per year due to the impact of climate change between 2030 and 2050. ${ }^{1}$ The Intergovernmental Panel on Climate Change, a large intergovernmental body dedicated to the various aspects of climate change, from impacts, risks, and response, identified several climate-related health risks, many of which have moderate-to-high evidence. ${ }^{2}$ These include increased deaths and injuries due to intense heat waves; increase in food-, water, and vector-borne diseases; malnutrition, especially in poorer areas; reduced labor productivity; and an overall negative impact on human health.

\section{Effects on Mental Health}

The effects of climate change on mental health have been mostly inconspicuous from discussion. The Lancet Commissions considers climate change the greatest challenge as well health opportunity of the 21st century. Apart from the physical health problems, climate change can directly and indirectly affect mental health through unpredictable weather events, rising levels of pollution and changes in social structure in terms socioeconomic status, immigration and acculturation stress, lack of social capital, and utilization of public health resources. ${ }^{3}$

The growing body of literature suggests that extreme weather events such as flash floods, hurricanes, forest fires, and other natural disasters can trigger stress-related disorders such as post-traumatic stress disorders (PTSD), anxiety disorders, feeling of
1,2Department of Psychiatry, Lokopriya Gopinath Bordoloi Regional Institute of Mental Health (LGBRIMH), Tezpur, Assam, India

Corresponding Author: Suhasini Das, Department of Psychiatry, Lokopriya Gopinath Bordoloi Regional Institute of Mental Health (LGBRIMH), Tezpur, Assam, India, Phone: +91 8884622783, e-mail: dassuhasini1908@gmail.com

How to cite this article: Das S, Pathak K. Climate Change and Mental Health: Where do We Stand? East J Psychiatry 2020;23(1):30-31.

Source of support: Nil

Conflict of interest: None

helplessness, depressive disorders, suicides, substance abuse, and complicated grief. ${ }^{4}$ Most of effects are immediately following the natural events and directly related to the threats to lives, but the long-term impacts on mental health are indirectly due to loss of livelihood and economic damages that can persist for years, even in developed areas. $^{5}$

All these has led to suggest a group of disorders called "Psychoterratic syndromes" which refers to mental conditions arising out of our relationship with the environment. One of these is called "Solastalgia" which refers to the distress experienced when a well-known environment has changed and no longer provides the same comfort. ${ }^{6}$ Few other proposed syndromes are "Nature deficit disorder" defined as the human costs of alienation from nature ${ }^{7}$ and "Ecoanxiety," also known as "Climate anxiety" or "Climate change anxiety" as the anxiety due to existential threats posed by climate. ${ }^{8}$ Although anxiety is an evolutionary phenomenon which helps us to identify threats and take measures in response, pathological anxiety can be maladaptive and interfere with an individual's ability to take rational decisions, in this case take effective measures to mitigate the risks posed by climate change. These terminologies will clearly require more efforts to be included in current diagnostic system but nonetheless are important for our understanding of this complex issue.

It has been suggested that both the direct and indirect effects of climate change will increase inequalities amongst various strata of the society, widening the gap between the rich and the poor. 
The major burden will definitely be felt by groups marginalized by race, gender, age, and wealth. ${ }^{9}$ One of the most contentious issue plaguing India is that of farmers' suicide. Although debt and subsequent financial burden is often cited as the leading cause, current research point toward the role of global warming and climate change behind many of the deaths. ${ }^{10}$ As most of the farmers are dependent on the monsoon and natural rainfall for irrigation purposes, extreme weather events such as cyclones, severe drought, floods, and ill-timed rainfalls lead to repeated crop failures, which subsequently increase their financial losses, the price of which is often paid by the farmers' lives.

\section{Is There a Silver Lining?}

In the wake of the growing awareness, many steps have been taken, which addresses the issue, albeit in a more indirect way.

In 2015, WHO released its "Operational Framework for building climate resilient health systems" where the goal is to "enhance capacity of health systems to protect and improve population health in an unstable and changing climate. ${ }^{111}$ In other words, it aims to improve coping and adaptation strategies to reduce vulnerability to climate-related challenges, to bring sustainability to population health in an unstable climate system. In the same year, the United Nations adopted the 17 Sustainable Development Goals (SDGs), out of which, three are specifically focused on ensuring healthy lives, creating a better future where "physical, mental, and social well-being" are achieved in keeping the WHO definition of health. The SDGs are an integrated approach to build a viable future for all. ${ }^{12}$

It is noteworthy that the Indian government has taken some serious steps in combating climate change. The National Action Plan on Climate Change (NAPCC) was launched on 30thJune, 2008 outlining eight National Missions on climate change which included building a sustainable habitat. Although there has been improvement in all the sectors, with keeping climate change at the center of all the projects, much is left to be done to tackle the threat that's looming over our heads. ${ }^{13}$

It has been suggested with proper planning of cities, use of energy efficient resources, increasing green spaces, and encouraging the transition to an adaptive and sustainable lifestyle will reduce the incidence of mental illnesses due to climate change, among other benefits. ${ }^{3}$ However, as the environmental effects of mental health are less visible than the physical ones, the task lies in making mental health issues more visible and apparent to researchers, practitioners and policy makers, particularly in the developing countries, who are most vulnerable to these consequences and who are least responsible to this crisis. ${ }^{14}$

\section{Conclusion}

Climate change is an issue which affects each and every aspects of our lives and its impact on psychological health is no less precarious. Mental health-related issues due to climate change increasingly gaining prominence amongst scientists and researchers around the globe and slowly but surely, everyone is recognizing its significance. Although gradual steps are being taken, these are very small compared to the magnitude of problem that the whole humanity faces today. It is important that both individual and collective actions are taken urgently to tackle this insidious threat if we want to provide healthy lives for our future generations.

\section{References}

1. Fact Sheets(Detail): Climate change and health. Geneva: World Health Organization. 2018. Available from https://www.who.int/ news-room/fact-sheets/detail/climate-change-and-health (Accessed on $24 / 03 / 2021$ ).

2. Smith KR, Woodward A, Campbell-Lendrum $D$, et al. Human health: impacts, adaptation, and co-benefits. In Field CB, Barros VR, Dokken DJ et al (eds) Climate Change 2014 Impacts, Adaptation, and Vulnerability. Part A: Global and Sectoral Aspects. Contribution of Working Group II to the Fifth Assessment Report of the Intergovernmental Panel on Climate Change, 2014 (pp. 709-754). Cambridge, United Kingdom and New York, NY, USA: Cambridge University Press.

3. Watts N, Amann M, Ayeb-Karlsson S, et al. The Lancet countdown on health and climate change: from 25 years of inaction to a global transformation for public health. Lancet 2018; 391(10120): 581-630. DOI: 10.1016/S0140-6736(17)32464-9. Epub 2017 Oct 30. Erratum in: Lancet. 2017 Nov 23. Erratum in: Lancet. 2020 Jun 6;395 (10239):1762. PMID: 29096948.

4. Padhy SK, Sarkar S, Panigrahi M, et al. Mental health effects of climate change. Indian J Occup Environ Med. 2015; 19(1):3-7. DOI: 10.4103/0019-5278.156997. PMID: 26023264; PMCID: PMC4446935.

5. Kessler RC, Galea S, Gruber MJ, et al. Trends in mental illness and suicidality after Hurricane Katrina. Mol Psychiatry 2008;13:374-384.

6. Albretch G. Chronic environmental change: emerging psychoterratic syndromes. In Weissbecker I. (eds.) Climate Change and Human Wellbeing. International and Cultural Psychology, 2011;pp.43-56. New York, NY: Springer. DOI: 10.1007/978-1-4419-9742-5_3

7. Louv R. Last Child in the Woods: Saving Our Children from Nature Deficit Disorder, 2006. Chapel Hill, NC: Algonquin Press.

8. Panu P. Anxiety and the ecological crisis: an analysis of eco-anxiety and climate anxiety. Sustainability. 2020;12(19):7836. DOI: $10.3390 /$ su12197836

9. Berry HL, Bowen K, Kjellstrom T. Climate change and mental health: a causal pathways framework. Int J Public Health 2010;55(2):123-132. DOI: 10.1007/s00038-009-0112-0. Epub 2009 Dec 22. PMID: 20033251.

10. Kaur L, Sharma P, Garg L. Causes and cure of farmer's suicide. Indian J Eco Dev. 2016;12(1a):305. DOI: 10.5958/2322-0430.2016.00081.0

11. World Health Organization. Operational framework for building climate resilient health systems. Geneva: World Health Organization 2015. Available from https://apps.who.int/iris/handle/10665/189951 (Accessed on 25/03/2021).

12. Sustainable Development. Department of Economic and Social Affairs. United Nations. Available from https://sdgs.un.org/goals (Accessed on 26/03/2021).

13. Rattani V, Venkatesh S, Pandey K, et al. India's National Action Plan on Climate Change needs desperate repair. Down to Earth. 2018 October 3; Sect. Climate Change.

14. Ingle HE, Mikulewicz M. Mental health and climate change: tackling invisible injustice. Lancet Planet Health 2020;4(4):e128-e130. DOI: 10.1016/S2542-5196(20)30081-4. PMID: 32353287. 